\title{
Strengthening faith during coronavirus: An Islamic perspective
}

\author{
Zainab Saherwala, DO
}

$\mathrm{R}$ amadan will be depressing this year," a patient told me as I entered the room for an evaluation. This is one of many similar reactions my patients expressed in March, when mosques began to close and social distancing parameters were put in place to limit the spread of coronavirus disease 2019 (COVID-19). Muslims began to adjust to new social norms, such as replacing warm hugs with waving hands from 6 feet away. They were suddenly advised to avoid century-long cultural practices, such as spending time with extended family, visiting the sick and the elderly, and meeting for Jummah (Friday) prayer at mosque. With increasing anxiety and uncertainty in the air, I began thinking about how the pandemic would psychologically affect Islamic spirituality, especially during Ramadan (the Islamic month of fasting) this year.

As a Muslim psychiatry resident working on an inpatient psychiatric unit and in a psychiatry consultation service during the COVID-19 pandemic, I often explore spirituality and faith with my patients as a way of providing supportive therapy for anxiety. Many of my Christian patients endorsed anxiety about how Easter would be "terrible" this year because they could not attend church. Upon hearing this, I realized that I could not picture a Ramadan during which I was not permitted to go to mosque. How was I supposed to provide supportive therapy for my patients when I also felt so uncertain? These concerns led me to take a step back and remind myself of what I frequently tell my patients when they feel hopeless: "With

every difficulty, there comes an opportunity to gain a new perspective."

\section{A time for spirituality}

When Ramadan began in April, many people who are Muslim and were working from home told me that it felt strange to have so much time during the day to pray, reflect, and read the Quran. Others mentioned that they enjoyed the peace of Iftar (breaking fast) at home, because they could avoid the hustle and bustle of this at mosque. Halfway through Ramadan, a Muslim patient I was treating reported that her "coronavirus anxiety" had improved as she began focusing her energy on Allah, rather than spending hours watching the news and obsessing over death tolls.

Due to the pandemic, many more opportunities for donating to those in need arose, which led my religious community to perform Zakat (providing charity) and send supplies to food banks in our area. Because of social distancing, Muslim families were able to spend more time preparing meals, learning together, and supporting each other. Although mosques were closed due to the pandemic, it seemed as though each home became its own gathering place for

LET YOUR VOICE BE HEARD

CURRENT PSYCHIATRY invites psychiatry residents to share their views on professional or clinical topics for publication in Residents' Voices. E-mail jbauer@mdedge.com for author guidelines.

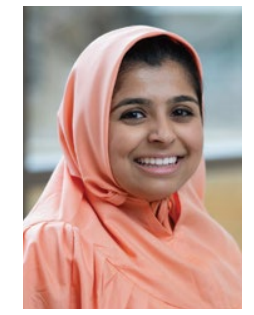

Dr. Saherwala is a PGY-3 Psychiatry Resident, Wright State University, Dayton, Ohio.

\section{Disclosure}

The author reports no financial relationships with any companies whose products are mentioned in this article, or with manufacturers of competing products.

doi: 10.12788/cp.0039 
Clinical Point

I believe resilience has grown stronger among Muslims worldwide during this pandemic spirituality, gratitude, and self-reflection. By the end of Ramadan, the values of selfdiscipline, empathy, and patience became self-evident.

\section{Increased attention to mental health among Muslims}

Psychologically, I believe resilience has grown stronger among Muslims worldwide during this pandemic. Along with adopting a positive mindset, Muslims have committed to creating their own routines to combat anxiety during this stressful time. The Salat (praying 5 times a day) and Taharat (cleanliness) that Islam emphasizes have been helpful in creating structure to offset the uncertainty and fear that is associated with COVID-19.

The discussion of mental illness, which previously has been regarded as a culturally stigmatized topic, has been gaining significant recognition within Islamic communities. Depression, anxiety, and self-care are now emphasized during virtual sermons, and contact information for mental health hotlines and professionals are being rapidly disseminated. There is now a greater sense of encouragement for people of Islamic faith to seek psychiatric help when needed.

Although COVID-19 has limited some social and physical religious practices, this pandemic has helped to strengthen faith and spirituality not only among Muslims, but also people of other faiths. During periods of stress, change, and uncertainty, it is important to remember that "With every difficulty, there comes an opportunity to gain a new perspective." Although mosques and churches continue to stay closed and anxiety persists, I can now confidently reassure my patients that through this experience we are becoming resilient and learning to value patience, gratitude, and empathy more than ever. 